\title{
MOVIMENTO E INATIVAÇÃO DO METRIBUZIN EM MATERIAIS DE DOIS SOLOS, SOB DIFERENTES DENSIDADES APARENTES
}

\author{
L.E.F. FONTES*, B. FERNANDES** e J.F. DA SILVA** \\ * Pesquisador da EMBRAPA. \\ ** Professor da Universidade Federal de Viçosa, \\ 36.570, Viçosa-MG. \\ Trabalho condensado da tese de M.S. do pri - \\ meiro autor. \\ Recebido para publicação em 24/03/80.
}

\section{RESUMO}

Numa série de ensaios em laboratório e casade-vegetação, estudou-se a mobilidade e a inativação do herbicida metribuzin em materiais de um Latossolo e de um Podzólico representativos de duas regiões do Estado de Minas Gerais, em função de diferentes densidades aparentes.

Ensaios biológicos foram utilizados para medir a inativacão e a mobilidade do metribuzin nos diferentes solos e densidades.

A densidade aparente alterou de forma pronunciada a quantidade de herbicida lixiviado através das colunas dos materiais dos solos estudados. Quanto maior a densidade, menor a quantidade de herbicida lixiviado.

A quantidade de herbicida que permaneceu biologicamente ativo ao longo da coluna foi diretamente relacionada com a densidade, em cada solo.

A mobilidade do metribuzin no material do Latossolo foi maior que no de Podzólico, em consequência de maior atividade coloidal deste.

UNITERMOS:

metribuzin, lixiviação, inativação, densida de de solo, atividade coloidal.

\section{SUMMARY}

MOVEMENT AND INACTIVATION OF METRIBUZIN IN TWO SOIL MATERIALS

WITH DIFFERENT BULK DENSITIES

The leaching and inactivation of metribuzin were studied with materials of two mineral soils at different bulk densities.

Plastic tubing of $7.25 \mathrm{~cm}$ diameter and 10 $\mathrm{cm}$ height were filled up with different amounts of soil to get different bulk densities.

One $\mathrm{kg} / \mathrm{ha}$ of a.i. of metribuzin placed on the surface area of the column was leached through these soil colums using $250 \mathrm{ml}$ of water.

The cotyledon disk bioassay method was used to detect the metribuzin leachet. The biological active metribuzin in the soil colunn at different depths, and the inativation ability of the soils were determined using the assay with cucumber (Cucumis sativus L.) as test-plant.
The increase of bulk density reduced the leaching and enhanced the biologically active metribuzin in the soil column.

Metribuzin was more mobil in the Red-yellow Latossol and more inactivated in the Red yellow Podzolic soils. KEYWORDS:

metribuzin, leaching, inactivation, bulk density, coloidal activity.

\section{INTRODUÇÃO}

A agricultura torna-se, cada vez mais, um fator essencial ao desenvolvimento sócio-econômico do País. Visando ao aumento da produtividade, pesquisas têm sido desenvolvidas em todos os setores agrícolas. Nessa luta constante por maiores produçôes, um dos obstáculos mais dificeis tem sido, sem dúvida, o controle das plantas daninhas.

O estudo do comportamento do herbicida no solo permite seu uso de forma mais racional. Sua mobilidade, por exemplo, pode determinar seletividade para determinada cultura ou maior eficiência para o controle de uma planta daninha especifica (10). Diferenças em adsorção e movimento podem ser atribuídas, em parte, à solubilidade do produto em água e à basicidade do meio, entre outros fatores. Essas propriedades podem alterar a entrada do composto na solução do solo e sua adsorção por partículas desse solo. Quanto maior for a solubilidade do herbicida em água, dentro de um mesmo grupo químico, maior será sua mobilidade. Outro aspecto que deve ser consi- 
derado nos estudos que envolvem herbicidas e o solo é a retenção e o movimento de água, que são diretamente influenciadas pela porosidade do solo.

Esforço especial tem sido feito para melhor entendimento do movimento e persistência de herbicidas no solo, sendo que investigaçôes recentes têm procurado conhecer melhor as interaçoes entre os herbicidas e os solos ou materiais de solos $(4,6,7)$. Vários trabalhos $(\mathbf{1}, \mathbf{3}, \mathbf{4}, \mathbf{5}, \mathbf{7}$, $15,17,19,20,21)$ têm mostrado um efeito quantitativo e qualitativo altamente influente dos colóides orgânicos e minerais do solo. Entretanto, especificamente para o metribuzin, relativamente pouca informação existe sobre o seu comportamento, no solo. Resultados têm indicado que a mobilidade e a inativação deste herbicida estão associadas ao conteúdo de areia, argila e matéria orgânica, bem como o estado de umidade do solo (13).

Deste modo, o presente trabalho foi desenvolvido objetivando estudar a inativação e mobilidade do metribuzin em materiais de solos sob diferentes densidades aparentes.

\section{MATERIAIS E MÉTODOS}

A pesquisa foi realizada com materiais de um Podzólico Vermelho-Amarelo Câmbico Dis- trófico, fase terraco e-de um Latossolo VermelhoAmarelo Distrófico, fase cerrado. Estudou-se, ainda, material de um solo orgânico, usado para comparação. Algumas características físicas e químicas são mostradas no Quadro 1 .

$O$ herbicida utilizado neste trabalho foi o metribuzin, 4-amino - 6-t-butil - 3-metiltio - 1,2,4 triazina - $5(4 \mathrm{H})$ - ona, formulado como pó molhável contendo $70 \%$ de i.a. (*).

Para os estudos de permeabilidade, distribuição do tamanho dos poros, e ensaio com o herbicida, foram preparad as colunas de solo em tubos de PVC rígido, com $10 \mathrm{~cm}$ de comprimento e $7,25 \mathrm{~cm}$ de diâmetro interno, correspondentes a um volume de $413 \mathrm{~cm} 3$

As densidades aparentes estudadas foram obtidas tomando diferentes quantidades de terra para encher os tubos de PVC, que for am secadas ao ar e passadas através de peneira de $2 \mathrm{~mm}$ de abertura. Para os cálculos das quantidades de terra para cada densidade, os valores foram corrigidos para "terra fina seca em estufa".

Os tubos de PVC foram pincelados com parafina em seu interior, antes de receberem a terra de cada solo, a fim de promover a formação de uma camada hidrofóbica, evitando o fluxo de água pelas paredes do tubo, permitindo maior precisão dos resultados. Na parte infe rior dos tubos, foi colocado um "papel de filtro" e uma camada de um tecido fino, presa por elástico, a fim de reter a terra e permitir a passagem da água e da solução.

Para os estudos de movimento e adsorção de herbicida, os tubos utilizados na montagem das colunas foram previamente seccionados em 4 partes, de $2,5 \mathrm{~cm}$ cada uma, e novamente interligados com fita adesiva impermeável. Em seguida, recobriu-se a parede interior do tubo com uma ca-

(*) Formulaçáo comercial Lexone

Quadro 1. Algumas caracteristicas fisicas e químicas dos solos estudados.

\begin{tabular}{l|c|c|c}
\hline \hline Análise Granulometrica \% de & Latossolo & Podzólico & Solo Orginico \\
\hline Areia grossa & 11 & 5 & 25 \\
Areia fina & 11 & 12 & 35 \\
Silte & 17 & 27 & 25 \\
Argila & 61 & 56 & 15 \\
Classificaçăo textural & Argila pesada & Argila & Franco-arenoso \\
\hline Análises Químicas & & & \\
\multicolumn{1}{c}{ Teores } & & & \\
\hline Matéria orgânica \% & 4,9 & 3,9 & 47,2 \\
pH em água (1:2,5) & 5,1 & 5,4 & 4,2 \\
Al trocível eq.mg/100g solo & 0,55 & 0,10 & 0,60 \\
Fósforo (P) ppm & 1,0 & 10,0 & 80,0 \\
Potássio (K) ppm & 30,0 & 114,0 & 71,0 \\
Callcio (Ca ${ }^{++}$eq.mg/100g solo & 0,1 & 4,1 & 13,7 \\
Magnesio (Mg ${ }^{++}$eq.mg/100g solo & 0,1 & 0,7 & 2,1 \\
\hline \hline
\end{tabular}


mada de parafina, para evitar que a solução se perdesse pelos cortes do tubo, não se distribuindo de maneira uniforme na coluna.

O solo orgânico foi estudado sob uma densidade apenas, pela dificuldade de obtenção de colunas com densidades aparentes mais elevadas e pelo fato de ser utilizado apenas como auxílio na discussão dos resultados.

A capacidade adsortiva dos solos foi avaliado, em casa-de-vegetação, seguindo o método utilizado por Silva (17). A planta-teste utilizada foi o pepino (Cucumis sativus L.), cultivar "Andai", plantado em copos plásticos, de área superficial e volume conhecidos. As diferentes doses do herbicida, calculadas à base da área superficial dos copos e expressos em g do i.a. por ha, foram incorporadas ao solo.

Os copos foram irrigados diariamente, alternando-se água destilada e solução nutritiva. Fo empregada a solução de Hoagland e Amon, modificada (11).

Quatorze dias após o plantio das sementes, as plantas foram cortadas rente à superficie do solo, determinando-se o peso de matéria fresca. Cada tratamento foi repetido três vezes, e o experimento duas vezes.

A concentração de metribuzin que provocou $50 \%$ de reducão do peso de matéria fresca das plantas (I.) foi determinada para cada tipo de solo, em gráficos de dose $\mathrm{x} \%$ de peso de matéria fresca, em relação à testemunha.

O movimento do metribuzin foi estudado promovendo sua lixiviação através de colunas de solo previamente saturadas por capilaridade. Após a saturacão do solo, aplicou-se $10 \mathrm{ml}$ de solução do herbicida, uniformemente distribuída no topo da coluna. A dose do herbicida utilizada foi de $1,0 \mathrm{~kg} /$ ha do i.a. calculado em função da área superficial da coluna.

Três horas após sua aplicação, o herbicida foi lixiviado com adição de $250 \mathrm{ml}$ de água destilada, volume equivalente a $60 \mathrm{~mm}$ de chuva. Para

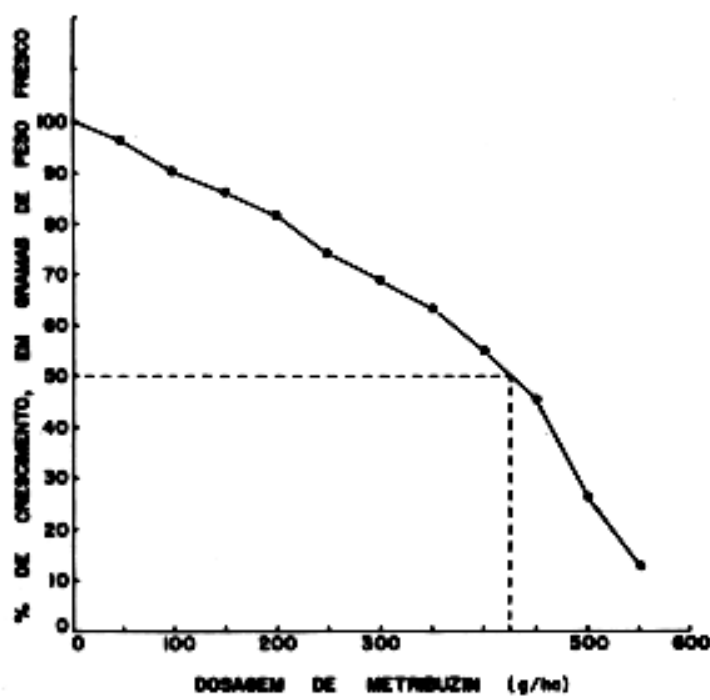

Figura 1. Resposta do crescimento, em peso de matéria fresca, de plantas de pepino a diferentes concentracões de metribuzin, no material do Solo Orgânico. a determinação quantitativa do herbicida lixiviado, o percolado foi submetido ao bioensaio, com discos de cotilédones de melancia (Citrullus lanatus (Thumb) Matsum e Nakai) segundo a metodologia de Truelove et alii, modificada por Silva et alii (18).

Após a percolação do herbicida, as colunas de solo foram desmontadas, determinando-se a quantidade de herbicida livre presente nos matenais dos solos em cada profundidade seguindo o mesmo método descrito para avaliar a capacidade adsortiva dos solos. Inicialmente determinouse a curva padrão de resposta do pepino ao metribuzin aplicado na areia lavada. Assim sendo, determinou-se a quantidade do herbicida presente nas diversas frações da coluna, em função das quantidades dos solos dessas diferentes frações adicionadas à areia lavada, necessários para reduzir $50 \%$ do peso de matéria fresca das plantas de pepino.

Quatorze dias após o plantio das sementes as plantas foram cortad as rente à superficie do solo, determinando-se o peso de matéria fresca para, através de interpolações gráficas, determinar a quantidade do herbicida biologicamente ativo nas diferentes frações das colunas.

Todos os tratamentos foram repetidos três vezes, e o experimento duas vezes.

\section{RESULTADOS E DISCUSSÃO}

As dosagens de metribuzin estimadas que causaram $50 \%$ de inibição no crescimento de plantas de pepino (I50) foram de 66, 78 e $425 \mathrm{~g}$ do i.a. por hectare, para os materiais do Latossolo, do Podzólico e do Solo Orgânico, respectivamente (Figuras 1 e 2).

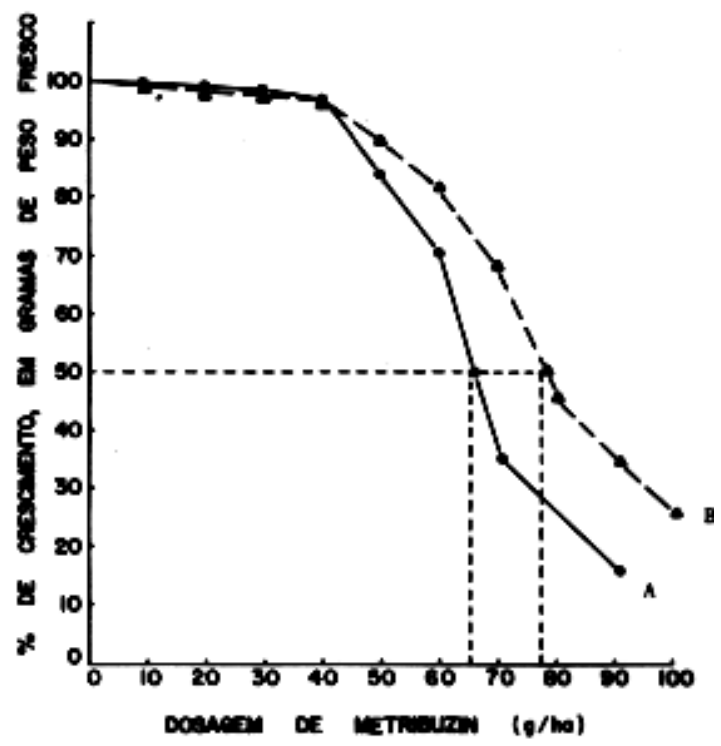

Figura 2. Resposta do crescimento, em peso de matéria fresca, de plantas de pepino a diferentes concentrações de metribuzin, nos materiais do Latossolo (A) e do Podzólico (B). 
Analisando as principais características dos solos estudados (Quadro 1), observa-se que a maior inativação do herbicida ocorreu no solo onde o conteúdo de matéria orgânica era extrema mente elevado (Figura 1). Nos outros dois solos não houve grande diferença nos resultados, apresentando, entretanto o material do Podzólico inativação um pouco mais elevada que a do Latossolo (Figura 2). Is so deve estar relacionado com a atividade diferencial dos colóides desses solos.

A densidade aparente influenciou a lixiviação, em ambos os solos estudados (Quadro 2). 0 aum ento da densidade provocou redução na quantidade de herbicida que passou através da coluna, para ambos os solos estudados. Isso pode ser explicado pelo efeito, princi palmente, da microporosidade (Figura 3) na permeabilidade à água (Figura 4). Observa-se que, à medida que aumenta a densidade, ocorre um aumento relativo na \% de poros menores, dificultando a movimentação da água. Isso está de acordo com Savage (13), que diz que a mobilidade do metribuzin depende do equilibrio estabelecido entre as moléculas do herbicida e os componentes coloidais do solo, e que este equilíbrio pode ser quebrado por restrição na drenagem interna, em razão da presença de camadas compactadas.

Quadro 2. Resultados médios da quantidade de herbicida lixiviado através das colunas $(\mu \mathrm{g})$, em função do solo e da densidade aparente.

\begin{tabular}{llcc}
\hline \multirow{2}{*}{ Solo } & \multicolumn{4}{c}{ Densidade A parente $\left(\mathrm{g} / \mathrm{cm}^{3}\right)$} \\
\cline { 2 - 4 } & 0,9 & 1,0 & 1,3 \\
\hline Latossolo & 26,65 a A & 15,68 b A & 5,50 c A \\
Podzólico & 18,32 a B & 13,55 b B & 4,20 c B \\
\hline \hline
\end{tabular}

Médias seguidas de diferentes letras minúsculas nas linhas e malúsculas nas colunas, diferem entre si, ao nível de $5 \%$ de probabilidade, pelo teste de Tukey.

Scott e Paetzold (14) encontraram grande efeito do que eles chamaram de "tortuosidade" do sistema na difusão do metribuzin. Com o aumento da densidade aparente, a compactação au- menta; logo, esse fenômeno também deve ser contribuido.

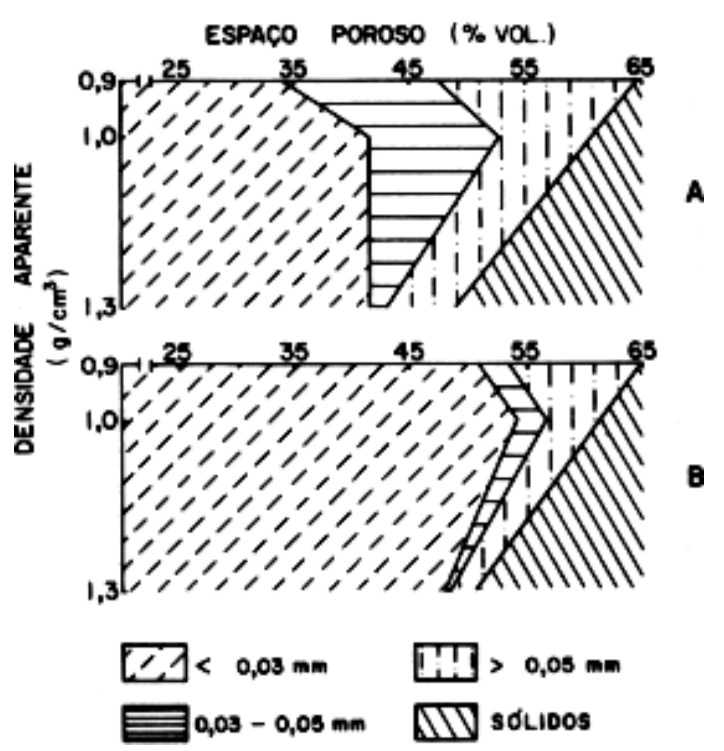

Figura 3. Efeito da densidade aparente na variação do espaço poroso total e na distribuição do tamanho de poros, nos materiais do Latossolo (A) e do Podzólico (B).

Comparando os dois solos dentro de uma mesma densidade, o Latossolo apresentou sempre maior lixiviação que o Podzólico (Quadro 2). A explicação es tá no maior poder de inativação deste, pela sua maior quantidade de poros com pequeno diâmetro (Figura 3). Estes, aumentando a taxa de água não disponivel para as plantas, provocaram menor liberação do herbicida. Esses resultados estão coerentes com os observados nos testes de capacidade adsortiva dos solos (Figura 2).

Observa-se que a variação ocorrida nas quantidades de herbicida lixiviada entre as densidades estudadas, num mesmo solo, foi maior no Latossolo (Quadro 2). Isso pode estar relacionado com o que se observa na Figura 4, onde a variação nas curvas de permeabilidade foi maior, também, no Latos solo. O Podzólico apresentou comportamento mais uniforme na permeabilidade e, como consequência suposta, uma menor variação no metribuzin lixiviado, entre as densidades estudadas. 


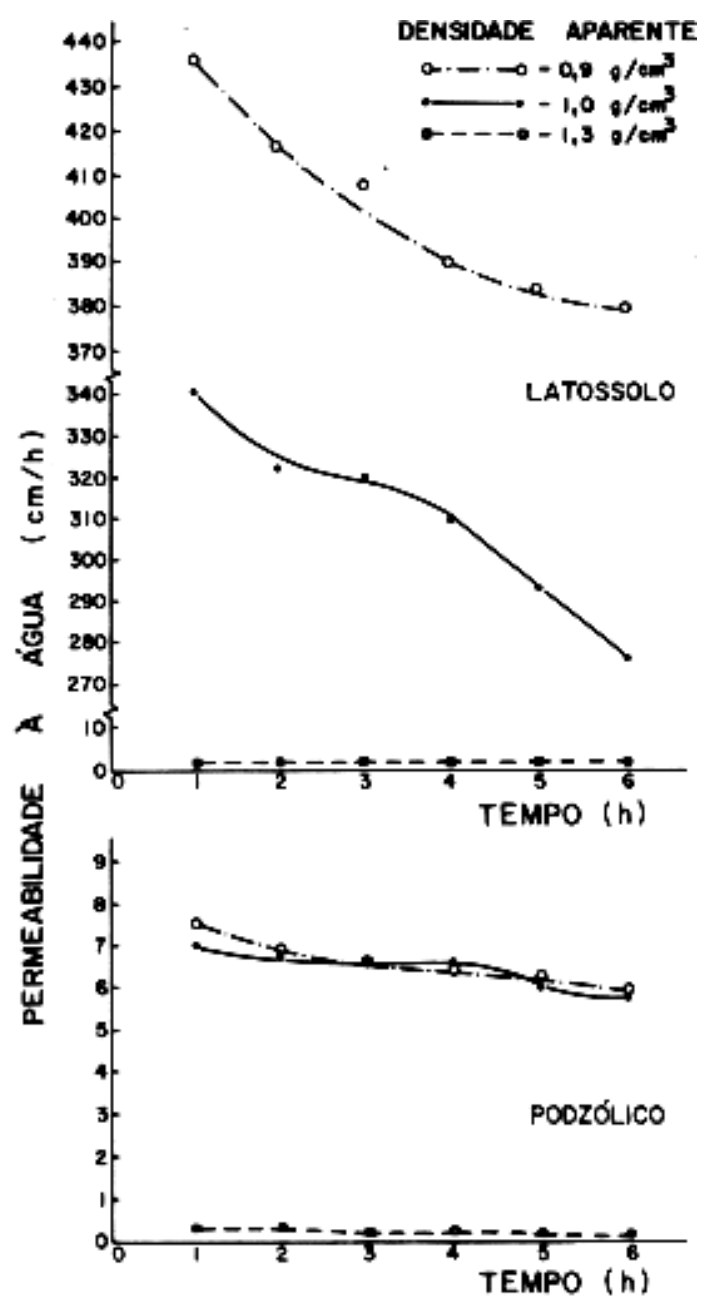

Figura 4. Permeabilidade dos materiais do Latossolo e do Podzólico à água, nas densidades aparentes estudadas.

A mobilidade do metribuzin foi também testada no material do Solo Orgânico, para que pudesse ser utilizado como comparação. O resultado encon trado foi que todo o herbicida aplicado ficou retido na coluna do solo, uma vez que sua presença não foi detectada no percolado dela obtido. $\mathrm{O}$ alto conteúdo de matéria orgânica desse solo (Quadro 1) foi a causa da elevada adsorção do herbicida. Esse resultado é coerente com a elevada inativação que esse material de solo apresentou (Figura 1). A dosagem utilizada (1,0 kg de i.a./ ha) foi insuficiente para permitir movi- mentação do herbicida além dos $10 \mathrm{~cm}$ de profundidade que tinha a coluna.

O material do Latossolo apresentou maior quantidade de herbicida biologicamente ativo que o do Podzólico, em qualquer densidade e profundidade considerada. Tal fato está relacionado com capacidade de inativação diferencial apresentada pelos dois solos, discutida anteriormente.

Observa-se (Figura 5) que a quantidade de herbicida biologicamente ativo aumentou com o aumento da densidade aparente. A explicação é que a compactação resulta num aumento relativo na percentagem de poros de pequenos diâmetros (Figura 3), alterando a geometria do sistema, provocando, então, dificuldade na movimentação de água, como pode ser visto na Figura 4. Com isso, maior quantidade de herbicida permaneceu retida na coluna.

Para o efeito de profundidades, analisado a partir das médias gerais de 13,2, $10,3,4,2$ e 3,7 microgramas de metribuzin biologicamente ativo, para as profundidades de 0 a $2,5 \mathrm{~cm}, 2,5$ a $5,0 \mathrm{~cm}$, 5,0 a $7,5 \mathrm{~cm}$ e 7,5 a $10,0 \mathrm{~cm}$, respectivamente, foi encontrada significância entre todas elas. Isso significa que a quantidade de herbicida livre decresceu com a profundidade, em todos os tratamentos estudados. Observa-se, ainda (Figura 5), que o herbicida disponivel para as plantas concentrou-se em maiores quantidades, até a profundidade de $5,0 \mathrm{~cm}$ e que, para a mesma profundidade, essa quantidade cresceu com o aumento da densidade aparente, em todos os tratamentos. O fato pode ser explicado pela dificuldade de movimentação do herbicida em solução, em função do aumento da compactação. Isso é interessante, considerando ser a faixa até $5,0 \mathrm{~cm}$, a mais importante no controle da maioria das plantas daninhas, pois é a que oferece condiçôes de germinação para suas sementes.

Nesse ensaio foram efetuados, ainda, testes com o material do Solo Orgânico. Os resultados mostraram grande inativação do metribuzin por parte desse solo, uma vez que apenas na profundidade de 0 a $2,5 \mathrm{~cm}$ foi encontrada pequena quantidade do produto livre. Nas outras profundidades 0 metribuzin não foi detectado. 

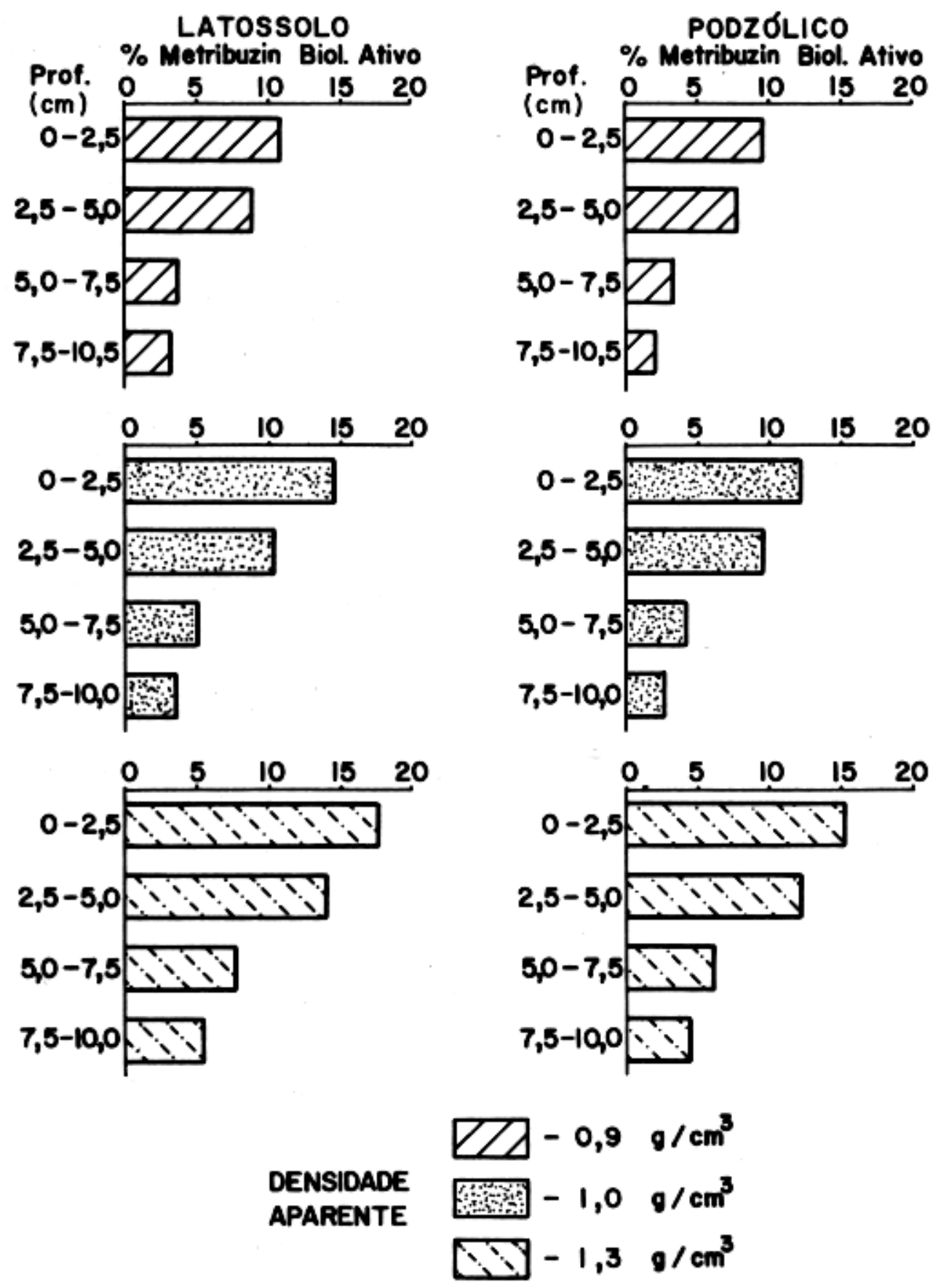

Figura 5. Quantidade de metribuzin biologicamente ativo ( $\mu$ g), nas diferentes profundidades, nos tratamentos diversos. 
Baseando-se nas discussões anteriores, tornam-se interessante alguns comentários sobre a relação manejo do solo: dosagem de herbicidas. Partindo do princípio de que a mobilidade e a adsorção dos herbicidas são fundamenta is na sua disponibilidade para as plantas, os resultados deste trabalho evidenciam a importância de uma dosagem correta em função do manejo a que o solo estiver sendo submetido. Se o manejo tender a provocar adensamento de camadas do solo, a dosagem do herbicida deverá ser diminuida, porque ele estaria disponivel em taxas maiores.

\section{LTERATURA CITADA}

1. Empresa de Pesquisa Agropecuária de Minas Gerais, EPAMIG - Recomendaçóes para o uso de herbicidas no Estado de Minas Gerais. Belo Horizonte, 1976. 57p.

2. Eshel, Y. \& Warren, G.F. - A simplified method for determining phytotoxicity leaching, and adsorption of herbicides in soil. Weeds, 15: $115-118,1967$.

3. Frissel, M.J. \& Bolt, G.H. - Interaction between certain ionizable organic compounds (herbicides) and clay minerals. Soil Sei., 94: 284-291, 1962.

4. Hance, R.J. - Observations on the relationship between the adsorption of diuron and nature of the adsorbent. Weed Res., 5: 108-114, 1965.

5. Hance, R.J. - The adsorption of urea and some of its derivatives by a variety of soils. Weed Res., 5: 98-107.

6. Harris, C.I. - Adsorption, movement, and plytotoxicity of monuron and s-triazine herbicides in soll. Weeds, 14: 6-10, 1966.

7. Kunze, G.W. Pesticides and clay minerals. In: Pesticides and their effects on soils and water.
Soil Science of America. ASA Special Publication n. ${ }^{\circ} 8,1966$. p.49-70.

8. Ladlie, J.S.; Meggitt, W.F. \& Penner, D. Effect of soll $\mathrm{pH}$ on metribuzin activity in the soil. Weed Science, 24: 505-507, 1976.

9. Leasure, J.K. Bioassay methods for 4-amino-3. 5.6-trichloropicolinic acid. Weeds, 12: 232-233, 1964.

10. Leistra, M.; Smelt, J.H. \& Zandvoort, R. Persistence and mobility of bromacil in orchad soil Weed Research, 15: 243-247, 1975.

11. Martins, C.E. Eficiència de utilizaçảo de potássio, cálcio e magnésio em 16 híbridos de sorgo (Sorghum bicolor (L.) Moench). UFV, Viçosa, 1978. 57p. (Dissertaçấ).

12. Parker, $C$. The role of weed science in developing countries. Weed Sci., 20: 408-413, 1972.

13. Savage, K.E. Adsorption and mobility of metribuzin in soll. Weed Science, 24: 525-528, 1976.

14. Scott, H.D. \& Paetzold, R.F. Effects of soil moisture on the diffusion coefficients and ativation energies of tritiated water, chloride, and metribuzin. Soil Sci. Soc. Am. Proc., 42: 23-27, 1978.

15. Sharon, M.S. \& Stephenson, G.R. Behavior and fate of metribuzin in eight Ontario soils. Weed Science, 24: 153-160, 1976.

16. Sherburne, H.R.: Freed, V.H. \& Frang, S.C. The use of $\mathrm{C}^{1+}$ carbonyl labeled 3(p-chlorophenyl)-1.1.-dimethyl-urea in a leaching study. Weeds, 4: 50-54, 1956.

17. Silva, J.F. da Herbicidal activity and selecti. vity of metribuzin. Lafayette, Purdue University, 1975. 58p. (Tese).

18. Silva, J.F, da; Fadayomi, R.O. \& Warren, G.F. Cotiledon disc-bioassay for certain herbicides. Weed Sci., 24: 250-252, 1976.

19. Talbert, R.E. \& Fletchall, O.H. The adsorption of some s-triazines in soils. Weeds, 13: 4652,1965 .

20. Warren, G.F. Curso Intensivo de Herbicidas. Viçosa, Imprensa Universitária, 1967. 89p.

21. William, R.D. \& Warren, G.F. Adsorçáo, movimento e vaporização de herbicidas. In: Controle de ervas daninhas. Viçosa, UFV, 1973. p.216-239. 